\title{
Percepção Ambiental de alunos das "Salas de Inclusão" na escola Liceu Paraibano, João Pessoa - PB, no contexto do paradigma da educação inclusiva
}

\author{
Environmental perceptions of "Rooms Inclusion" students at the Liceu Paraibano School, João Pessoa - PB, in the \\ context of the inclusive education paradigm.
}

\section{Hermes de Oliveira Machado Filho',2, Juliana dos Santos Severiano², Silvana Barbosa de Azevedo ${ }^{3}$, Icaro Arcênio de Alencar Rodrigues'}

'Instituto Federal de Educação, Ciência e Tecnologia da Paraíba - IFPB - PB - Brasil

${ }^{2}$ Universidade Federal Rural de Pernambuco - UFRPE - PB - Brasil

3Universidade Federal do Rio Grande do Norte - UFRN - RN - Brasil

\begin{abstract}
Resumo
O presente artigo tem como objetivo provocar uma reflexão sobre o paradigma da educação inclusiva, a partir do estudo da concepção de meio ambiente levantada na escola Liceu Paraibano em João Pessoa - PB. Esta pesquisa foi desenvolvida com o intuito de realizar uma caracterização da percepção ambiental dos alunos, porém tornou-se um polêmico debate sobre a problemática da inclusão pedagógica de portadores de necessidades especiais no ensino regular. O processo de inclusão deve ser entendido como um posicionamento político e social em prol da educação especial, e que vem crescendo no ambiente escolar, de forma a alcançar relações mais igualitárias para todos. Porém, a pesquisa se deparou com o contexto real dessas "salas de aula de inclusão". Percebeu-se que para se evitar que alguém esteja em risco de ser excluído de um dado contexto na sala de aula, acaba excluindo outro sujeito do processo de ensino-aprendizagem, transcorrendo de toda forma em situações de desvantagem, seletividade e preconceitos.
\end{abstract}

Palavras-chave: Percepção Ambiental, Educação Ambiental, Educação Inclusiva, João Pessoa.

\begin{abstract}
Environmental resources are undergoing a process of decay constant and is doing a great degradation in natural ecosystems. One of the major problems of today is a lot of waste. The objective was to sensitize the students so outgoing with active classes to develop a sense of critical environmental issues in order to develop solutions to environmental problems. The work was performed at Educandário Learning to Learn, private school elementary school in the city of Bananeiras-PB. The subjects were a group of fifteen students in the 5th year of Primary school. The same occurred in the months of November to December 2012. The methodologies used were dynamic with: balloons, and fighter-word puzzle to develop environmental issues with the students. The dynamics of facilitated dialogue balloons in room encouraging them to talk, ask questions and give their opinion. Puzzles allowed students to make a reflection about the pollution of water and soil, waste that is exposed in nature, the benefits of separate collection for recycling the materials and the time it takes for some materials decompose. Moreover, the word search awoke in educating the spirit of teamwork, attitude key to behavior change society. We conclude that dynamic games and contributed to the process of recovery and formation of environmental awareness of the students, helping in changing behaviors and facilitated the assimilation of content by students so extroverted.
\end{abstract}

Keywords: education, environmental awareness, teaching and learning. 


\section{INTRODUÇÃO}

A percepção ambiental é uma tomada de consciência do ambiente pelo homem, ou seja, como esse sujeito se auto define e percebe o ambiente, o espaço que ele está localizado e que interage (BASSANI, 2001).

Cada pessoa entende, reage e responde de forma diferente frente às ações sobre o ambiente. As respostas são, portanto, resultado das percepções, dos processos de aprendizagem, análise e crítica de cada indivíduo. Embora nem todas as manifestações psicológicas sejam evidentes, suas representações são constantes e afetam nossa conduta, sendo, na maioria das vezes, agidas inconscientemente (BASSANI, 2001; COOL SALVADOR et al., 1999).

Para Bassani (2001), percepção não é uma mera sensação dada pelos órgãos sensoriais. $\mathrm{O}$ ser humano tem a capacidade de ver, de ouvir e de sentir tudo ao seu redor; enfim, tudo aquilo que pode estimular os sentidos é uma forma de percepção, mas, o perceptível é somente aquilo que a nossa mente atribui significado.

A percepção é altamente seletiva, exploratória e até antecipadora. Nesse sentido, considera-se como uma atividade perceptiva, aquela que explora, seleciona, compara, antecipa todo o perceptível (COOL SALVADOR et al., 1999). No continuum, entre a percepção e a inteligência, está intercalada à atividade perceptiva, que nos enseja trabalhar com o objetivo entre o plano perceptivo e o representativo.

Dessa forma, as atitudes que qualquer sujeito realiza só se efetivam porque estão formatadas previamente em sua mente como se tivessem sido pré-programadas, pelo processo educativo, por exemplo. É como se houvesse um mecanismo indutor a tais realizações, que no caso seria a percepção adquirida (COOL SALVADOR et al., 1999).

Partindo dessa perspectiva, o presente trabalho realizou um estudo que buscou identificar a percepção ambiental dos alunos das "salas de inclusão" que cursão o ensino médio na escola pública Liceu Paraibano, no Centro de João Pessoa - Paraíba; uma turma mista de alunos surdos e ouvintes em uma mesmo ambiente de sala de aula.

A escolha do objeto de pesquisa está na necessidade de se averiguar se existe deficiência na compreensão e aprendizagem desses alunos em perceberem a situação da problemática ambiental que vem ocorrendo atualmente no mundo e da importância da nossa colaboração enquanto cidadão para conservação dos recursos naturais.
Além de, pesquisar se esses sujeitos correlacionam/percebem a necessidade de se ter um meio ambiente sadio e a quem eles atribuem esse estado da problemática ambiental.

Essa pesquisa busca contribuir para o desenvolvimento do tema Meio Ambiente e Educação Ambiental nas escolas, de forma a permitir o acesso dessas informações a todos os alunos, através do emprego metodologias adequadas e acessíveis que possam transpor qualquer "barreira física" e/ou ideológica.

\section{REVISÃO TEÓRICA}

\section{I A Questão Ambiental: Educação, Percepção e Entendimentos para a Sustentabilidade}

Atualmente, há um crescente interesse em direcionar esforços para melhoria da qualidade de vida da sociedade no mundo, na maioria das vezes, à custa da exploração dos recursos naturais. Com o aumento das grandes cidades, começou-se a perceber o crescimento dos impactos ambientais gerados pela degradação da natureza e poluição do meio ambiente, causando um desequilíbrio desastroso entre o homem e seu meio, em prol do "desenvolvimento" da sociedade de consumo (VESENTINE, 1992).

A solução para essa questão ambiental tem sido considerada cada vez mais importante e um dos aspectos mais relevantes para essa resolução é, sem dúvida, a tomada de consciência por parte de todos nós como agentes modificadores do meio ambiente (SILVA; GUERRA, 2003).

É de fundamental importância trazer essa abordagem para as escolas, sendo considerada de forma sistematizada e desenvolvida num contexto transversal (PNC, 1998), de modo que o aluno perceba que a questão ambiental está interligada aos diversos ramos disciplinares, além de ser uma preocupação de todos nós para um futuro melhor e que todos têm algo a contribuir para solucionar esse problema, começando a fazer a sua parte individualmente/coletivamente.

Uma forma de trabalhar essa problemática é desenvolver atividades de Educação Ambiental (EA), como sendo uma ferramenta imprescindível de formação humanística para mudança de hábitos, valorização da natureza e conservação dos recursos naturais (BRASIL, 1998).

De acordo com a Constituição Federal de 1988 , no inciso VI, do parágrafo $1^{\circ}$ do artigo 225 , a Educação Ambiental deve ser considerada em todos os níveis de ensino de forma a desenvolver sua importância e adotar posturas pessoais e 
comportamentais ambientalmente sustentáveis perante o meio ambiente. O descompromisso com esse artigo caracteriza o não comprimento do Estado para com o ensino e para com o bem estar de todos (BRASIL, 1997).

A EA induz o sujeito à adesão de posturas ecologicamente corretas e, certamente, funciona como uma ferramenta para o desenvolvimento sustentável da sociedade, estimulando uma articulação entre as pessoas em prol da questão ambiental, desenvolvendo estratégias anti-degradatórias ao meio ambiente (BRASIL, 1998). Dessa forma, atividades com esse intuito tendem a ser imprescindíveis em busca da sustentabilidade do homem na Terra.

\subsection{Educação Inclusiva: um Problema para a Escola ou da Educação Brasileira?}

Considera-se como inclusão social o processo pelo qual a sociedade se adapta para poder incluir, nos seus sistemas sociais gerais, pessoas com necessidades especiais. Este é um processo bilateral, no qual as pessoas que se encontram no estado de exclusão e a sociedade, buscam identificar os problemas, encontrar soluções para estes e efetivar a equiparação de oportunidades para todos (SASSAKI, 1997).

Apesar da educação exercer papel fundamental no processo de inclusão social, encontra-se num eterno desafio. Como conseguir que todos os alunos tenham acesso à educação de forma igualitária e de qualidade para desenvolver suas habilidades e competências necessárias no dia-adia? Tudo isso, de forma a que se respeitem no alunado, suas diferenças culturais, sociais, étnicas e, mais atualmente, suas condições especiais. E por mais contraditório que seja, é a própria escola que compromete decisivamente este processo de ensino-aprendizagem (SANTOS, 2003).

A educação inclusiva se iniciou no Brasil, oficialmente, em 1854 com incentivos do governo de Dom Pedro II, que criou organizações em prol de ajudar os portadores de deficiência, como chamados na época. Só a partir de meados do fim do século XX, por iniciativa do Ministério da Educação e Cultura (MEC), que se iniciou uma política de educação especial, devido a diversas reivindicações de pais e organizações de portadores de necessidades especiais, que é a nomenclatura aceita atualmente (JOVER, 1999). No Estado da Paraíba, o impulso maior em prol dos portadores de necessidades especiais foi com a criação da Fundação Centro Integrador de Apoio ao Portador de Deficiência (FUNAD), em 1991.

Em 1994, na Conferência Mundial sobre
Necessidades Educativas Especiais, na cidade de Salamanca, na Espanha, originou a Declaração de Salamanca, na qual se ratificou o compromisso com a Educação Para Todos, incluindo as pessoas com necessidades especiais como partícipes do sistema comum de educação (ABENHAIM, 2005).

No Brasil, o processo de inclusão de surdos em escolas regulares, ou seja, juntamente com alunos ouvintes, foi de certa forma deliberada inicialmente no ano de 2004, em algumas escolas públicas polos, a exemplo da Liceu Paraibano, em João Pessoa, Paraíba.

A Resolução $\mathrm{N}^{\circ} 02$ do Conselho Nacional de Educação (2001) ratificou a entrada de alunos com necessidades especiais no ensino regular, assegurando a todos esse direito. E nessa perspectiva, a nova política de Educação Inclusiva impõe uma reestruturação do sistema educacional que objetive a transformação da escola em um espaço democrático e competente para se trabalhar com esses discentes, proporcionando a todos, a apropriação do conhecimento, gerando oportunidades para a inclusão (CARDOSO, 2003).

Para alunos que apresentam a surdez como deficiência, deve haver uma adequação do ambiente escolar para recebê-lo, uma vez que este aluno é acostumado com outro idioma em seu cotidiano (FELIPE, 2006), e saber recepcionar também a um novo ator no ambiente escolar, que é o intérprete de Linguagem Brasileira de Sinais (LIBRAS), que precisa estar bem preparado para assumir um compromisso importante na transposição do ensino falado para o ensino gestual (ROSA, 2006).

Esse quadro da educação brasileira é um grande desafio a ser trabalhado, pois pela Constituição Federal de 1988, capítulo II, seção I, do artigo 205, a educação deve ser levada como um "direito de todos e dever do Estado e da família, será promovida e incentivada com a colaboração da sociedade (...)". Por si, este artigo já estaria valendo para enquadrar os deficientes, mas o artigo 208, inciso III, ratifica esse direito com a ressalva que "(...) atendimento educacional especializado aos portadores de deficiência, [deve ser] ${ }^{*}$ preferencialmente na rede escolar de ensino" (BRASIL, 2008) ( ${ }^{*}$ complemento nosso). Porém, essas adequações facilitadoras que se espera, ainda não estão sendo efetivadas do ensino dessas escolas inclusivas.

A problemática do processo inclusivo parece estar na organização política na maioria dos Estados do país. Falta preparo para o atendimento desse novo público no meio escolar, a começar pelo mau estruturamento dos ambientes escolares, falta de recursos e adaptações do currículo, despreparo e falta de incentivos aos profissionais 
da área de ensino (desde o professor ao porteiro) a acolher e cativar esse público, pouca preocupação no planejamento das aulas entre professores e intérpretes; são vários os problemas nesse âmbito (PALAMIN et al., 2001).

A questão ainda mais preocupante, e o que chama a atenção da academia, é o fato do anulamento da figura do professor em sala de aula para os alunos surdos. Basicamente, os intérpretes de LIBRAS apresentam autonomia, tendo que saber desenvolver todo um conhecimento multidisciplinar durante o tempo de serviço para que o aluno surdo possa entender os conceitos abordados em sala de aula (PALAMIN et al., 2001). Para o aluno surdo, quem é o professor da disciplina será sempre o intérprete de LIBRAS.

Segundo Jover (1999), uma escola pode tentar remanejar o discente que apresenta deficiência para outra escola mais capacitada ou que já tenha a inclusão como prática escolar. Se não há essa alternativa, a direção escolar pode optar em solicitar via MEC, algum material disponível para atendimento desse(s) aluno(s), através da capacitação de professores interessados ou recomendações de parcerias, vias universidades e ONG's, para integrar o aluno especial. No caso do Estado da Paraíba, a FUNAD é o órgão mais bem enquadrado para prestar esse apoio à escola, através de consultorias ou capacitações para o corpo escolar receber o portador de deficiência com mais dignidade.

Por último, a Lei Federal $\mathrm{N}^{\mathrm{o}} 7.853$ dispõe sobre o apoio aos deficientes e sua integração social, definindo o preconceito como crime. Nesse sentido, nenhuma escola ou creche pode recusar, sem justa causa, o acesso do deficiente à instituição, sendo sujeita a multa e prisão por 4 anos do gestor (JOVER, 1999). O problema para desenvolver o processo de inclusão está na falta de preparação dessas escolas para atender a esse público.

\section{METODOLOGIA}

A pesquisa foi realizada com alunos que cursavam o $1^{\circ}$ ano do ensino médio no turno noturno na escola pública Liceu Paraibano, localizada em João Pessoa, Paraíba. A percepção ambiental dos alunos foi investigada seguindo a metodologia baseada na teoria de Sauvé (1997), que trata do estudo das concepções sobre o tema meio ambiente, e nos estudos aplicados de Silva e Guerra (2003) e Machado-Filho e Guerra (2007), que também utilizam esse método de interpretação em suas pesquisas.
O trabalho de Sauvé (1997) apresenta uma abordagem que orienta sobre como analisar as diversas práticas do discurso ambiental, esclarecendo sobre as concepções tipológicas de representação, nas diversas correntes de pensamento sobre o meio ambiente. Nesta perspectiva, a autora lista 6 (seis) análises de categorias ambientais fundamentais que podem englobar o meio ambiente:

1 - Como Biosfera, pois o ambiente abrange um fato global onde há consciência sobre a interdependência entre os seres vivos e o ambiente físico, numa perspectiva dos problemas ambientais;

2 - Como Natureza, que trata do ambiente como um local puro, intocado, primitivo, perfeito, "lindo". É como uma relíquia, ou monumento, que deve apenas ser observado, admirado e respeitado, sem provocar mudança alguma, pois assim deixaria de ser o que é;

3- Como Recurso, sendo uma fonte biofísica estratégica, para a utilização humana, onde há interesse pela sua abundância e longevidade. É passado como algo que deve ser gerenciado por autoridades pela preocupação quanto a limitação e escassez destes recursos;

4 - Como problema, está relacionado à atual situação em que se encontram nossas cidades, o campo, os resquícios da natureza, ou seja, do mundo. O enfoque é dado ao apelo pela mudança, pela transformação da realidade, contra a ameaça que o mundo pode estar passando num futuro não muito distante. Pode ser considerada, também, uma visão catastrófica à sociedade pela excessiva poluição ambiental e escassez dos recursos naturais;

5 - Como um Lugar para se Viver, esta concepção está atrelada ao âmbito local, como por exemplo, a nossa casa, a nossa escola, ao local de trabalho, etc. É o espaço de apropriação do sujeito, por isso é uma ambiente restrito, mas que deve ser cuidado, pois afinal, "pertencemos a ele"; e 6 - Como Projeto Comunitário, sendo um local dividido pela coletividade humana, mas que clama pelo apoio participativo da comunidade em questão para resolução de problemas e condução de soluções adequadas em prol do desenvolvimento social e ambiental.

Foi aplicado um questionário semi-estrutu- 
rado com sete perguntas, entre perguntas abertas e de múltipla escolha livre. Porém, para a análise do presente trabalho, buscou-se se ater apenas a primeira questão que trata do conceito de meio ambiente. Dessa forma, foi solicitado que os alunos respondessem a seguinte pergunta: $O$ que é meio ambiente para você?

A amostra que compôs a investigação constou de um total de 35 alunos pesquisados, sendo 24 alunos ouvintes e 11 alunos surdos. A escola apresenta uma intérprete de LIBRAS que acompanhando os alunos nos momentos das aulas.

A investigação compreendeu uma análise quantitativa das respostas dos alunos. Para uma melhor explicação geral do contexto, as respostas foram transcritas, sem nenhuma alteração da ideia, nem da grafia das palavras. Os dados foram tabulados e organizados, quantificado as frequências das respostas e calculados os percentuais gerais.

Para o contexto de interpretação sobre a análise das respostas dadas pelos alunos surdos, foi verificada a estruturação da coesão-coerência da frase e extraída uma interpretação inferencial sobre a construção da ideia do aluno, baseado na obra de Sampaio (2007).

Como análise interpretativa dos resultados, optou-se em deixar separadas as respostas dos alunos surdos dos ouvintes, de forma a estabelecer um comparativo em se verificar se há ou não uma (de) similaridade nas tendências das respostas e do tipo de percepção ambiental dos grupos.

\section{RESULTADOS E DISCUSSÃO}

\section{I Discussão quantitativa sobre a percepção dos alunos no contexto ambiental}

A partir das respostas analisadas elaborou-se a tabela 1, que enquadra as opiniões dos alunos, com os percentuais gerais para cada grupo verificado (ouvintes e surdos).

\subsection{Análise quali-quantitativa das respostas dos alunos ouvintes}

Analisando a princípio as respostas dadas pelos alunos ouvintes, pelo que se pode perceber, as concepções entre os alunos estiveram divididas entre as categorias de meio ambiente como Natureza $(45,8 \%)$ e como Lugar para se Viver $(37,5 \%)$, sendo as mais representativas entre as respostas.

Os alunos apresentam opiniões bem definidas, alguns defendem a idéia de meio ambiente num contexto de ambiente preservado, bonito, isento da ação humana. Esta concepção de meio ambiente como Natureza trás como principal foco perceptivo apenas elementos naturais, tais como os elementos básicos da natureza (água, terra, vento) e suas formas (rios, montanhas, ar). Objetiva também a ideia de um ambiente que não foi tocado ainda pela ação do homem, dada sua perfeição, ou seja, é uma visão que não condiz mais com a realidade, pois não há espaço na Terra que o homem já não tenha modificado a um nível global (VESENTINE, 1992). Essa concepção é

Tabela 1 - Respostas dos alunos (ouvintes e surdos) sobre a percepção do que o ambiente representa a eles.

\begin{tabular}{lc|c|c|c}
\hline \multirow{2}{*}{$\begin{array}{c}\text { Categorias, segundo } \\
\text { Sauvé (1997) }\end{array}$} & \multicolumn{2}{c}{ Ouvintes } & \multicolumn{2}{c}{ Surdos } \\
\cline { 2 - 5 } & $\begin{array}{c}\text { Frequência das } \\
\text { Respostas }\end{array}$ & $\begin{array}{c}\text { Percentual das } \\
\text { Respostas }\end{array}$ & $\begin{array}{c}\text { Frequência das } \\
\text { Respostas }\end{array}$ & $\begin{array}{c}\text { Percentual das } \\
\text { Respostas }\end{array}$ \\
\hline Biosfera & 3 & 12,50 & - & 0,00 \\
Natureza & 11 & 45,83 & 1 & 9,09 \\
Recurso & - & 0,00 & - & 0,00 \\
Problema & 1 & 4,16 & 5 & 45,45 \\
Lugar para se Viver & 9 & 37,50 & 2 & 18,18 \\
Projeto Comunitário & - & 0,00 & - & 0,00 \\
Desconexa & - & 0,00 & 2 & 18,18 \\
Não Responderam & - & 0,00 & 1 & 9,09 \\
\hline TOTAL & 24 & $100,00 \%$ & 11 & $100,00 \%$ \\
\hline
\end{tabular}


uma visão primitivista, tal qual pensada pelos povos colonizadores quando "descobriram" a América e a Oceania, que não percebiam que a presença dos povos primitivos fosse também uma ação dominadora sobre o ambiente, como o é (VESENTINE, 1992).

Para endossar essas ideias, são destacadas as respostas desses alunos para uma melhor análise qualitativa, sobre a percepção do meio ambiente para esse grupo de alunos:

(1) "Local de energias positivas e que deve ser preservados todas as formas."

(2) "São animais, plantas, rios, mares é muitas outras coisas da natureza"

(3) "Local Natura sem poluição"

(4) "O ambiente pra mim é um ambiente natural sem poluição com ar puro. Um ambiente livre."

(5) "É tudo o que envolve a natureza. Tudo o que for natural"

(6) "É tudo aquilo que nos cerca, como: as florestas, os rios, lagos, etc, e que agente tem de cuidar e preservar."

(7) "Animais, florestas, rios e mares."

(8) "Tudo o que está relacionado à natureza."

(9) "Muito importante, pois é onde vivem os animais e plantas."

(10) "Tudo que existe ao nosso redor, em específico a parte natural como florestas, cachoeiras, pois para mim tudo o que foi construído pelo homem não conta muito como meio ambiente"

(11) "É o meio em que vivemos em que nos relacionamos é tudo aquilo que contém vida e participa para o progresso, evolução, e desenvolvimento de algo. Ex: natureza em geral"

Como se pode perceber, as respostas dos alunos são bem alusivas à concepção de meio ambiente como algo onde impera a natureza a cima de tudo (5) (8) (10) (11), puro, sobrenatural (1), um lugar onde há a presença de animais e plantas (2) (6) (9), além de rios, montanhas, mares etc. (7), que deve se encontrar sempre limpo, sem ação de efeitos degradatórios ou poluição (3) (4). É uma tendência que simplifica o conceito de meio ambiente remetendo a uma concepção de natureza como algo intocado, que deve apresentar suas características originais. É essa ideia que Guerra e Abílio (2006) chamam quando dizem que esses sujeitos relacionam meio ambiente como sinônimo de natureza.
A outra parte representativa dos alunos ouvintes defende a ideia do local, ou seja, o meio ambiente a partir do espaço mais próximo do sujeito, o meio ambiente como Um lugar para se viver $(37,5 \%)$.

Desta forma, podem-se verificar respostas que trazem o contexto de um meio ambiente de forma mais próxima da realidade do aluno, um espaço geográfico que ele tem acesso, que ele pode intervir. Ao se colocar nas respostas a palavra "local" ou "lugar" logo nos remete a um ponto específico do espaço, mas, obrigatoriamente, esses locais e lugares são ambientes apropriados pelos alunos, ou que fazem parte do imaginário perceptivo. A presença humana é destacada como algo fundamental neste caso, o contexto do local-lugar ligado à natureza não faz parte dessa categoria.

Há a cisão do paradigma em se considerar o meio ambiente como algo distante do ser humano, ou sinônimo de natureza, ou fonte de exploração que permeia sobre a ideologia utilitarista do sistema capitalista. Esta categoria representa algo pessoal, há um sentimento de identidade embutido nas respostas. seguintes:

As respostas dadas pelos alunos foram às

(1) "É o meio onde vivemos, onde tem animais, arvores e tudo mais"

(2) "O meio em que vivemos, mas com o tempo vieram as transformações"

(3) "É tudo o que nós vemos, ao nosso redor"

(4) "É tudo o que está a nossa volta"

(5) "É tudo o que está em volta de nós"

(6) "É um lugar bem conservado"

(7) "É tudo que nos cerca como: rios, lagos, mares e principalmente sítios, fazendas e chácaras, por que é através delas que podemos ter condições de vida melhor"

(8) "ambiente, em si, é um local acho que não precisa ter a ver com arvores com verde. É um ambiente um local"

(9) "É tudo o que nos cerca, pode ser um meio natural ou urbano"

O meio ambiente como um lugar para se viver é colocado como um local definido seja pelo seu espaço e pelo seu objeto. Tanto se delimita uma área como necessariamente tem de haver o sujeito homem se inserindo na afirmativa, bem como todos os outros componentes naturais para esse processo. É o que se verifica nas respostas dos alunos, que pode ser um lugar ligado diretamente com a natureza (1) (7), ou um lugar qualquer abs- 
trato (3) (4) (5) (6) (8) (9), mas correspondente a um anseio pessoal e também pode ser um lugar que sofreu transformações (2), provavelmente, transformações derivadas da ação humana.

A categoria meio ambiente numa visão de Biosfera é uma concepção mais abrangente e maximizadora da construção de conexões entre a natureza e o espaço transformado a nível global. Essa categoria foi pouco representativa entre as respostas dos alunos (12,5\%), tomando como base geral, essa categoria é a mais completa e complexa para o entendimento do aluno, em perceber que as questões ambientais atingem uma esfera global em todas as ações que o homem desenvolve.

(1) "É tudo o que está em nossa volta, os rios, os lagos, as montanhas, nós e as transformações feitas pelo ser humano"

(2) "O meio ambiente é tudo pra mim. Por isso eu preservo o meio ambiente si nós mesmos não cuidar quem vai cuidar. Agente tem de fazer a nossa parte"

(3) "É o espaço geográfico, que forma a paisagem natural da terra ou o meio em que vivemos"

O meio ambiente como Biosfera estabelece uma interdependência entre os componentes envolvidos. Necessariamente é um conceito abstrato, mas que inter-relaciona homem-naturezatransformações (1), pode ou não ser tão explícito (3), mas se percebe pela forma que se expressa pela escrita. Esse conceito pode ser ainda mais complexo quando se torna algo tão grandioso (mas vago) (2), a tal ponto que se torna difícil definir a totalidade das variáveis que compõem o meio ambiente.

A categoria de meio ambiente como Problema não foi considerada representativa na pesquisa $(4,2 \%)$, pela baixa frequência verificada nas respostas dos alunos; só apresentou uma única resposta ("É ver rios limpos, as ruas também, ver as pessoas não destruindo as flores e as pessoas não sujarem e nem prejudicarem a cidade"). O meio ambiente como Projeto Comunitário ou como Recurso não apresentou resposta e dois dos alunos não responderam à pergunta.

\subsection{Análise das respostas dos alunos surdos}

A aquisição da linguagem, tanto da fala como da escrita, é um momento marcante. A criança constrói aos poucos o seu sistema linguístico, que acontece com o convívio familiar, e assim vai processando os códigos sociais e aprende a se comunicar. Nas crianças surdas esses fatos não acontecem naturalmente, o que acarreta inúmeros traumas e problemas em seu processo educacional e de aquisição de uma linguagem escrita (SAMPAIO, 2007).

Nesse sentido, os surdos apresentam sérias dificuldades em seu processo de letramento que chegam até a impedir o avanço no fluxo de escolarização.

Fernandes (1990), em pesquisa sobre o desempenho linguístico com alunos surdos, verificou que estes tinham inúmeras dificuldades com a língua escrita, tais como uso impróprio de verbos, preposições, e uso restrito de estruturas de coordenação e subordinação. Segundo a autora, estas dificuldades refletem a falta de contato linguístico, e não como naturais do surdo.

Brito (1995) e Silva (2001) acrescentam que a experiência bilíngue dos surdos, que aprendem a LIBRAS e a Língua Portuguesa, além do aprendizado da linguagem de sinais escrita, tem grande influência nas características dos textos escritos por estes.

A seguir são transcritas, literalmente, as respostas dadas pelos alunos surdos na pesquisa, para uma melhor discussão dos dados:

(1) "São as condições bióticas e abióticas em que vivo"

(2) "Eu gosto muitos lagoa"

(3) "Sempre as que escola muito gosto tudo"

(4) "O que é porque precisar faltou água, ar e saúde. O que é importante água sentir vida"

(5) "O porque ar saúde importante não tem mais pouco grande não tem"

(6) "O importante árvore na natureza que bom pessoa ar é ambiente corporal em de árvore"

(7) "É importante mais bom ar pouca porque mais ar não muito. Pouca a importante gostar bom ar muito livre eu estar sentir vida"

(8) "ar, televisão, sou, rua agua, lixo"

(9) "porque ambiente bom mais importante verde cidade limpo precisa pessoa ajudar me ar vento!"

(10) "O porque bom saude ar verdade"

De acordo com as respostas dadas pelos alunos surdos, pode-se evidenciar que a categoria mais representativa para o grupo é de que meio ambiente está conectado a algum Problema (aproximadamente $45 \%$ das respostas). Os alunos reproduzem a ideia de que os conflitos sócio-ambientais, os problemas relacionados à poluição, 
queimadas, devastações, epidemias, extinções, entre outros problemas provocados pelo homem, são os únicos fatos que se pode relacionar como fazendo parte do ambiente. É uma visão real, catastrófica, negativa e característica da nossa sociedade atual, mas não deixa de ser uma visão reducionista, pois alguns desses processos degradatórios são essenciais para a vida do homem, o problema é insustentabilidade instaurada pelo modo de produção vigente (VESENTINE, 1992).

As respostas 4, 5, 7, 9 e 10 fazem referência à questão da poluição e à importância da saúde devido ao fato, principalmente, da perda de qualidade de ar. $\mathrm{O}$ meio ambiente nessas questões é encarado como um problema.

Duas outras categorias dividem as respostas dadas pelos alunos, são elas: meio ambiente como Lugar para se Viver $(18,18 \%)$ e respostas desconexas $(18,18 \%)$; em seguida, meio ambiente como natureza $(9,09 \%)$ e aqueles que não responderam (9,09\%).

Percebe-se, rapidamente, que na maioria das respostas há falta de coesão na estruturação das frases. Para interpretar essas respostas, Sampaio (2007) encoraja que não importa a coesão das respostas, mas, sim, a busca por outros caminhos para se transitar pelo sistema linguístico de forma respeitosa e intuitiva, mas crítica.

Igualmente, Silva (2001) afirma que é possível construir sentidos por meio de hipóteses, sendo que a coesão é um dos recursos que permitem uma reconstrução dos sentidos.

A única, entre as 10 (dez) respostas amostradas, de forma coesa é a frase do aluno 1, apresentando um construto claro e conciso. Representa uma visão ecológica simplificada, mecanicista, mas que contempla de forma satisfatória a pergunta geradora da pesquisa. Apresenta em sua ideia o meio ambiente como elementos, que mais se aproxima da concepção indicadora de biosfera, conforme Sauvé (1997).

A concepção do meio ambiente como natureza pode estar exposta na resposta 2 , que apesar de não estar bem definida, sugere a intenção de um meio ambiente como um lugar agradável e belo. É provável que a lagoa que o aluno esteja se referindo, seja uma que fica próxima à escola, assim, esse aluno, certamente, esta exprimindo que gosta dessa lagoa específica. Dessa forma, na resposta 2 o meio ambiente estaria sendo referido como um lugar para se viver.

A resposta 6 é um tanto confusa, pois leva a indagar duas possibilidades: a de relacionar o conceito de meio ambiente como natureza ou como biosfera. A resposta traz elementos que afirmam a importância da árvore; mas, logo em seguida, surge uma relação com o ar, como se o ar fosse derivado da árvore, o que é uma relação assertiva, na intenção de reduzir a massa de ar como sinônimo de oxigênio atmosférico produzido pela fotossíntese vegetal. Porém, para generalizar e tentar enquadrar a resposta em apenas uma categoria, a primeira intenção deve prevalecer como apontam Machado-Filho e Guerra (2007).

As respostas 3 e 8 foram consideradas desconexas devido ao fato de não se estabelecer coesão nem coerência no entendimento frasal. E a resposta do aluno 11 estava em branco, não foi contabilizada.

\section{CONCLUSÕES}

A pesquisa apresentou que a concepção dos alunos ouvintes difere dos alunos surdos. Enquanto alunos ouvintes percebem o meio ambiente como um sinônimo de natureza, ou alunos surdos correlacionam meio ambiente sempre a problemas ambientais. Ambas as visões não são consideradas erradas, mas são restritivas e não representam a realidade, por isso, devem ser mais bem esclarecidas para esses alunos de forma a não reproduzirem essas ideias.

Dessa forma, é fundamental que os agentes que representam a coletividade do sistema de ensino, avaliem continuamente as práticas pedagógicas, no sentido de repensar procedimentos metodológicos mais acessíveis a essa nova "cara" da sala de aula. Alternativas estas, que propiciem a fixação dos conteúdos e direitos, e provoque um melhor entendimento dos conteúdos para esse novo público na sala de aula, essa nova "presença" de um grupo que foi historicamente excluído do ambiente escolar. Somos agora, nada mais nada menos, que sujeitos históricos desse processo.

No reconhecimento da prática do educador, a prática pedagógica tem de estar em consonância com paradigmas que tornarão a sala de aula/escola mais inclusora ou não. Assim, faz-se necessário a adoção de uma flexibilidade curricular, de um incentivo profissional para o seu melhor preparo, capacitações direcionadas e permanentes, trabalhar uma vivencia mais co-participativa com todos os agentes que prevêem atender a esses aspectos.

Sugere-se, também que, de modo geral, a língua de sinais seja ofertada para os alunos surdos desde as séries iniciais, assim como os familiares tenham acesso a essa língua, e os professores dominem a linguagem de sinais, de modo que este possa conviver num meio linguístico natural, con- 
tribuindo para uma melhor desenvoltura linguística e, certamente, uma maior inclusão social.

\section{REFERÊNCIAS BIBLIOGRÁFICAS}

ABENHAIM, E. Os caminhos da inclusão: breve histórico. In: MACHADO, A. M. et al. (Org.). Psicologia e Direitos Humanos: educação inclusiva, direitos humanos na escola. São Paulo: Casa do Psicólogo, Conselho Federal de Psicologia, 2005. p. 39-53.

BASSANI, M. A. Fatores psicológicos da percepção ambiental. In: MAIA, N. B. et al. (Orgs.). Indicadores Ambientais: Conceitos e Aplicações. São Paulo: EDUC/COMPEC/INEP, 2001.

BRASIL. Constituição Federal do Brasil de 1988. Disponível em: < http://www.culturabrasil.org/zip/ constituicao.pdf $>$. Acesso em: 27/02/2008.

Lei Federal no 7.853/89. Dispõe sobre o apoio às pessoas portadoras de deficiência, sua integração social, sobre a Coordenadoria para a Integração da Pessoa Portadora de Deficiência - CORDE, institui a tutela jurisdicional de interesses coletivos ou difusos dessas pessoas, disciplina a atuação do Ministério Público, define crimes, e dá outras providências.

Ministério da Educação. Resolução n ${ }^{\circ}$ 2 do Conselho Nacional da Educação e Câmara de Educação Básica (CNE/CEB), de Fevereiro de 2002. Institui Diretrizes Nacionais para a Educação Especial na Educação Básica. Brasília: Ministério da Educação, 2002.

A Implantação da Educação Ambiental no Brasil. Brasília: MEC, 1998.

Conferência Nacional de Educação

Ambiental. Brasília: MEC, 1997.

BRITO, L. F. Por uma gramática de línguas de sinais. Rio de Janeiro: Tempo Brasileiro - UFRJ, Departamento de Linguística e Filologia, 1995. 271p.

CARDOSO, R. S. Apoio pedagógico ao surdo incluído no ensino regular. In: CONGRESSO SURDEZ E ESCOLARIDADE: DESAFIOS E REFLEXÕES. II CONGRESSO INTERNACIONAL DO INES. VIII SEMINÁRIO NACIONAL DO INES, 2003, Rio de Janeiro. Anais...Rio de Janeiro: Estudos e
Pesquisa do INES, 2003. p. 129-133

COLL SALVADOR, C. (Org.). Psicologia da Educação. Porto Alegre: Artes Médicas Sul, 1999.

FELIPE, T. A. Os processos de formação de palavras na LIBRAS. Educação Temática Digital, Campinas, v.7, n.2, p.200-217, jun. 2006.

FERNANDES, E. Problemas linguísticos e cognitivos do surdo. Rio de Janeiro: Agir, 1990. 162p.

GUERRA, R. A. T.; ABÍLIO, F. J. P. Educação Ambiental na Escola Pública. João Pessoa: Foxgraf, 2006. 233p.

JOVER, A. Inclusão: qualidade para todos. Revista Nova Escola, São Paulo, v. 15, n. 123, p. 8-17., jun./ jul. 1999.

MACHADO-FILHO, H. O.; GUERRA, R. A. T. Como os alunos ingressantes no curso de Geografia da UFPB percebem o ambiente e a conservação dos recursos naturais. In: IV SEMAGEO - Semana de geografia da UFPB, 2007, Paraíba. Anais... Paraíba: UFPB, 2007.

PALAMIN, M. E. E.; BORTOLETO, R. H.; RODRIGUES, O. M. R. P.; MOTTI, T. F. G.; CASTANHO, R. M. Resultados de uma investigação acerca da inclusão escolar do deficiente auditivo. In: SEMINÁRIO SURDEZ E DIVERSIDADE SOCIAL, 2001, Rio de Janeiro. Anais... Rio de Janeiro: INES, Divisão de Estudos e Pesquisas, 2001.

ROSA, A. S. A (Im) Possibilidade da fidelidade na interpretação da língua brasileira de sinais. Educação Temática Digital, Campinas, v.7, n.2, p.123-134, jun. 2006.

SAMPAIO, M. J. A. A Construção de textos na escrita de surdos: estratégias do sujeito na transição entre dois sistemas lingüísticos. 2007. 93f. Dissertação (Mestrado em Letras) - Centro de Ciências Humanas, Letras e Artes, Universidade Federal da Paraíba, João Pessoa, 2007.

SANTOS, M. P. A formação de professores no contexto da inclusão. In: CONGRESSO SURDEZ E ESCOLARIDADE: DESAFIOS E REFLEXÕES. II CONGRESSO INTERNACIONAL DO INES. VIII SEMINÁRIO NACIONAL DO INES, 2003, Rio de Janeiro. Anais... Rio de Janeiro: Estudos e Pesquisa do INES, 2003. pp. 63-70. 
SASSAKI, R. K. Inclusão - construindo uma sociedade para todos. Rio de Janeiro: WVA, 1997. 76 p.

SAUVÉ, L. Educação ambiental e desenvolvimento sustentável: uma análise complexa. Revista de Educação Pública, v.6, n.10, p.72-102, jun./dez. 1997.

SILVA, M. da P. M. A construção de sentidos na escrita do aluno surdo. São Paulo: Plexus, 2001, p. 105 .

SILVA, Y. S.; GUERRA, R. A. T. A concepção de meio ambiente e educação ambiental dos estudantes de geografia da UFPB. In: X SIMPÓSIO DE GEOGRAFIA FÍSICA APLICADA, 2003, Rio de Janeiro. Anais...Rio de Janeiro: UERJ, 2003.

VESENTINI, J. W. O ensino da Geografia e as mudanças recentes no espaço geográfico mundial. 2 ed. São Paulo: Ática, 1992. 